Revista Energia na Agricultura

ISSN 1808-8759

\title{
CLIMATOLOGIA DE TEMPESTADES NA ÁREA CENTRAL DO ESTADO DE SÃO PAULO USANDO RADAR METEOROLÓGICO *
}

ANA MARIA GOMES HELD ${ }^{1} \&$ JOÃO FRANCISCO ESCOBEDO ${ }^{2}$

RESUMO: Uma climatologia para as tempestades observadas na área central do Estado de São Paulo foi determinada através da utilização do software TITAN - Thunderstorm, Identification, Tracking, Analysis and Nowcasting, desenvolvido no NCAR - National Center for Atmospheric Research e implementado no IPMet. Distribuições de frequencia dos parâmetros que caracterizam as propriedades dessas tempestades, tais como volume, área, altura dos topos dos ecos, refletividade máxima e média, bem como velocidade e deslocamento dos sistemas precipitantes, foram determinados para limiares de refletividade $>25,30$ e 40 $\mathrm{dBZ}$, e volume $>30 \mathrm{~km} 3$. A distribuição espacial desses parâmetros mostrou, pela primeira vez para a área central do Estado de São Paulo, a existência de regiões preferenciais de concentração de maior atividade convectiva, durante os verões analisados. A distribuição sazonal para o volume de precipitação evidenciou um período convectivo mais ativo durante o verão de 1998-1999 em comparação ao período de 19992000. A proximidade de aquíferos, aparece como um fator importante no favorecimento dessas áreas de concentração de atividade convectiva e que poderiam explicar a distribuição de máximos observados numa faixa paralela ao longo do rio Tietê, e numa área menor próximo a região de Ourinhos, divisa com o estado do Paraná. Informações sobre a distribuição espacial dos volumes de precipitação, se disponível, permitiriam o monitoramento contínuo sobre a eficiência hídrica numa determinada região monitorada por radar meteorológico. A distribuição espacial para as alturas dos topos dos ecos de precipitação também fornece uma informação direta sobre a distribuição da atividade convectiva numa área e no presente estudo é corroborada pela distribuição espacial para as refletividades, confirmando os resultados existentes na literatura que destacam a região metropolitana de Campinas como uma das regiões preferenciais de atividade convectiva intensa no Estado de São Paulo.

Palavras-chave: Estatística de eventos climáticos, precipitação pluvial, distribuição espacial de chuvas.

\footnotetext{
1 * Instituto de Pesquisas Meteorológicas/UNESP - Rua Raja Gebara, 1-55, apto. 94D 17018-550 Bauru SP ana@ipmet.unesp.br

${ }^{2}$ Departamento de Recursos Naturais/FCA/UNES
} 
STORM CLIMATOLOGY IN THE CENTRAL AREA OF THE STATE OF SÃO PAULO, BRAZIL, USING METEOROLOGICAL RADAR *

SUMMARY: A climatological characterization of storm properties during two summer seasons, viz. 1998-1999 and 1999-2000, based on observations from the Bauru S-band Doppler radar, was obtained from the TITAN Software of the National Center for Atmospheric Research (Boulder, Co), implemented at IPMet. Parameters, such as mean volume, mean area, mean and maximum echo tops, mean and maximum reflectivity, as well as speed and direction of precipitating systems were determined using the reflectivity $>25,30$ and $40 \mathrm{dBZ}$ and a volume $>30 \mathrm{~km} 3$ as thresholds for storm identification. For the first time, the spatial distributions of these parameters were determined in the central State of São Paulo, based on radar observations. It was found that some preferential areas, where most of the convective activity was concentrated during the study period, were located along the Tiete River. The mean maximum reflectivity field has highlighted preferential regions for convection to develop over the metropolitan area of Campinas, which in turn was reinforced by the distribution of the echo tops and reflectivity $>40 \mathrm{dBZ}$.

Keywords:Rradar precipitation, precipitation climatology, storm properties.

\section{INTRODUÇÃo}

O conhecimento sobre a distribuição espacial da precipitação pluvial e sua frequência para uma determinada região é de extrema importância ao considerarmos as práticas agrícolas. A maioria dos estudos existentes na literatura especializada foi realizada utilizando dados de redes pluviométricas convencionais. Neste estudo os aspectos climatológicos da precipitação na região central do Estado de São Paulo são analisados tendo por base as informações coletadas com um radar meteorológico localizado em Bauru.

Uma breve revisão de trabalhos que enfocam estudos climatológicos, baseados em informações de radar meteorológico pode ser encontrada em Gandú (1984), o qual apresenta um estudo sobre a distribuição estatística dos ecos de radar observados na região leste do Estado de São Paulo. Os resultados apresentam o regime de chuvas observado em relação à grande escala predominante destacando o deslocamento predominante das células convectivas na região, de oeste para leste, com velocidade média de $7 \mathrm{~m} / \mathrm{s}$. Chaudhry et al. (1996) apresentaram um estudo sobre a distribuição de chuvas convectivas na região central do Estado usando dados do antigo radar banda-C de Bauru, concentrando suas análises em duas regi- 
ões, sendo uma localizada ao longo do rio Tietê e uma outra numa região de relevo acentuado, ambas a uma distância de 82 e $113 \mathrm{~km}$ do radar, respectivamente. Os resultados evidenciam uma variação diurna da precipitação sobre a área central com um período de maior ocorrência de chuvas convectivas entre $17 \mathrm{e}$ 20 horas (horário local). A velocidade de deslocamento das células convectivas varia de 20 a $50 \mathrm{~km} / \mathrm{h}$, sendo a média dessas velocidades igual a $42 \mathrm{~km} / \mathrm{h}$, um valor superior quando comparado ao encontrado por Gandú (1984), para as células de precipitação sobre a região leste do Estado de São Paulo.

As características dos ecos de radar durante o período do Experimento TroCCiBras - Tropical Convection and Cirrus Brazil em 2004, utilizando uma metodologia objetiva para a identificação e rastreamento das tempestades foram determinadas por Gomes e Held (2005). Os resultados evidenciaram que durante o período do experimento houve um predomínio de pequenas tempestades, com volume médio menor que $500 \mathrm{Km}^{3}$ e uma duração média menor que 2 horas, indicando atividade convectiva predominantemente isolada, típica para a estação de verão na região central do Estado de São Paulo. Uma precipitação média $20 \%$ menor que a média climatológica foi confirmada por medidas convencionais de precipitação realizadas no IPMet e também por uma distribuição de densidade de descargas elétricas, que nesse período foi menor que a média climatológica obtida para o período de 1999 a 2003 (NACCARATO et al., 2004). O campo médio e o de anomalia de refletividade para a área de alcance dos $240 \mathrm{~km}$ do radar de Bauru foram obtidos por Figueiredo (2005), cujos resultados enfatizam a existência de regiões preferenciais de máximos de atividade convectiva, destacando a região metropolitana de Campinas, onde se concentrou a maior freqüência de refletividades em excesso de $45 \mathrm{dBZ}$, associadas à precipitação intensa que ocorre na região.

No presente estudo é feita uma análise para a caracterização climatológica das tempestades na área central do Estado de São Paulo, durante os verões de 1998-1999 e 1999-2000, usando uma metodologia objetiva para sua identificação e rastreamento. Para a análise obteve-se as distribuições de freqüência e espacial para os vários parâmetros que resumem as propriedades das tempestades, tais como volume, área, altura do topo dos ecos, refletividade máxima e deslocamento e direção das tempestades.

\section{MATERIAL E MÉTODOS}

O volume de chuva produzido por nuvens convectivas está relacionado, de alguma forma, à extensão em área e ao tempo de vida dessas nuvens. As áreas de eco são definidas a partir da escolha de um determinado limiar de refletividade e para o presente estudo selecionou-se limiares de refletividade de 25 , 30 e $40 \mathrm{dBZ}$. Os volumes estimados pelo radar são obtidos dos valores de refletividades transformados em taxas de precipitação usando a relação de Marshall e Palmer (1948), $Z=200 \mathrm{R}^{1.6}$, onde $\mathrm{Z}$ é a refletividade 
equivalente em $\mathrm{mm}^{6} \mathrm{~m}^{-3}$, e R é a taxa de precipitação em $\mathrm{mm} / \mathrm{h}$. Os volumes são calculados sobre cada ponto de grade, multiplicando-se a taxa de precipitação pela área elementar definida pelos pontos de grade a partir do limiar de refletividade selecionado usando sucessivas varreduras.

\subsection{Dados Utilizados}

Os dados utilizados no estudo foram coletados pelo radar meteorológico banda-S Doppler locali-

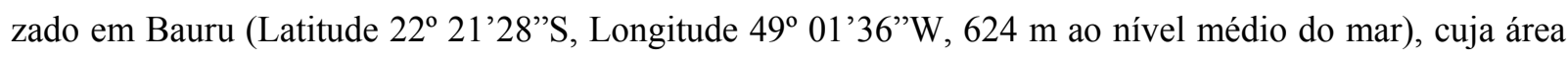
de alcance quantitativo é ilustrado pela Figura 1.

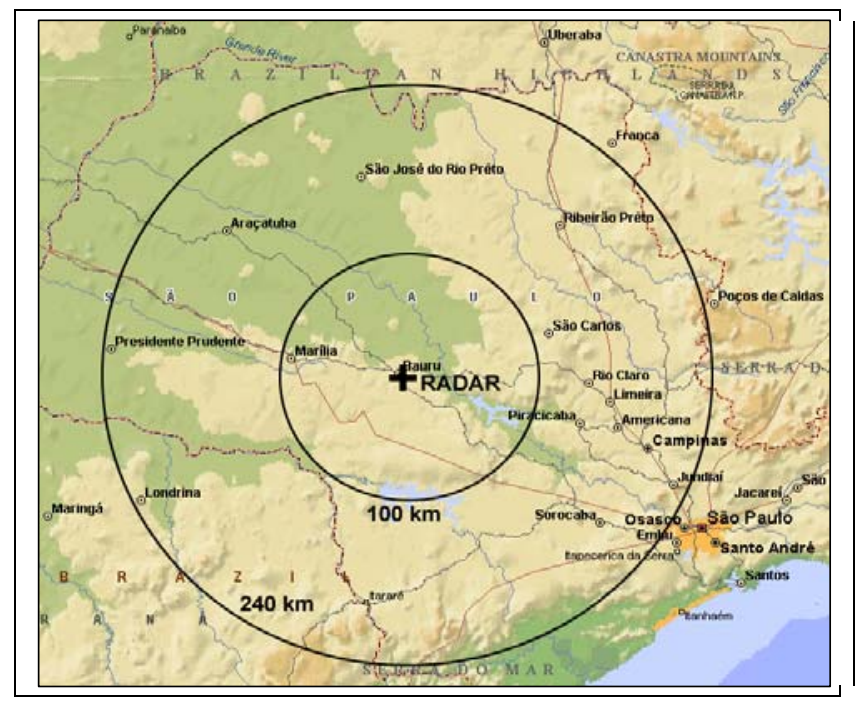

Figura 1 - Área selecionada para o estudo, raio de alcance de $240 \mathrm{~km}$ a partir do radar meteorológico Doppler de Bauru.

Suas características principais são: abertura de feixe de $2^{\circ}$, operando em modo vigilância num raio de $450 \mathrm{~km}$ de alcance e realizando varreduras volumétricas num raio de $240 \mathrm{~km}$ utilizando 11 elevações $\left(0,3^{\circ}\right.$ a $\left.35^{\circ}\right)$, com resolução radial de $1 \mathrm{~km}$ e azimutal de $1^{\circ}$. A resolução temporal de coleta dos dados é de 15 minutos ou menos, registrando e armazenando as informações de refletividade, velocidade radial e largura espectral. O mínimo sinal detectável (MDS) do radar é em torno de -109 dBm sendo que no alcance máximo não-ambíguo de $240 \mathrm{~km}$ a refletividade mínima detectável é 14,6 dBZ o que corresponde a uma taxa de precipitação de $0,30 \mathrm{~mm} / \mathrm{h}$ de acordo com a relação de Marshall e Palmer (1948), considerada 
aqui para a determinação das taxas de precipitação. Nenhuma correção, para as variações que ocorrem em relação ao preenchimento do feixe com a distância, foi considerada no estudo.

Foram eliminadas da análise, observações do radar contaminadas pela presença de propagação anômala (AP), tendo sido observado que em média, os horários preferenciais em que a mesma foi detectada ficaram próximos às primeiras horas do dia, entre $00 \mathrm{~h}$ e $07 \mathrm{~h}$. Foram utilizadas no processamento todas as áreas de ecos excedendo ao limiar de refletividade selecionado que compuseram os rastros de tempestade dentro do raio de alcance dos $240 \mathrm{~km}$ do radar Doppler de Bauru, para os períodos de 01 de outubro de 1998 a 31 de março de 1999 e de 01 de outubro de 1999 a 31 de março de 2000.

As propriedades características média dos aglomerados de ecos para os limiares de refletividade variando de 25, 30 e $40 \mathrm{dBZ}$ foram determinadas utilizando o módulo estatístico Track2Ascii do sistema de software TITAN (DIXON; WIENER, 1993) e a partir daí obteve-se as relativas distribuições de frequencia. Para a distribuição espacial dessas propriedades utilizou-se o módulo estatístico TrackGridStat do TITAN, que permite uma análise dos rastros das tempestades para um período de vários meses ou anos, propiciando portanto análises espaciais sazonais das propriedades relativas às tempestades numa região monitorada por radar.

O número de tempestades observadas durante o período estudado ficou em torno de $5 \times 10^{3}$ (limiar de $40 \mathrm{dBZ}$ ) a $10^{4}$ (limiar de $25 \mathrm{dBZ}$ ), respectivamente. Para a apresentação dos resultados foi selecionado o limiar de $30 \mathrm{dBZ}$, para se estabelecer um cotejo entre os resultados previamente obtidos por Gomes e Held (2005), destacando as diferenças e similaridades entre os períodos analisados e ainda, comparar os mesmos resultados com os existentes na literatura especializada, para outras regiões do globo.

\section{RESULTADOS E DISCUSSÃO}

\subsection{Propriedades Características das Tempestades}

\subsubsection{Volume}

As distribuições das freqüências relativas para os volumes observados para as tempestades identificadas pelo limiar de $30 \mathrm{dBZ}$ foram obtidas e são apresentadas nas Figuras 2a e 2b. 


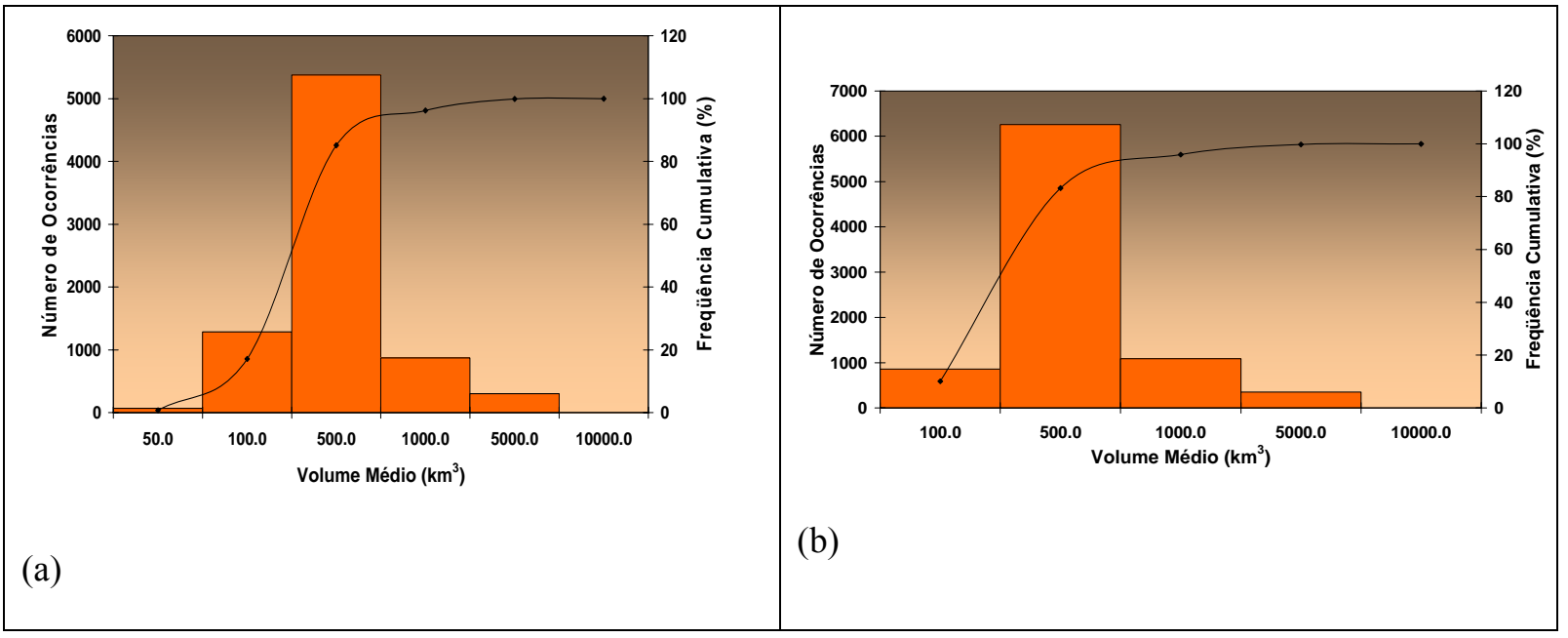

Figura 2 - Distribuição de freqüência do volume das tempestades ${ }_{30 \mathrm{dBZ}}\left(\mathrm{km}^{3}\right)$, para os verões de (a) 1998 1999 e (b) 1999-2000, em intervalos de 31-50; 51-100; 101-500; etc.

O volume médio obtido para as tempestades é de 300,5 e $326,0 \mathrm{~km}^{3}$, respectivamente para os verões de 1998-1999 e 1999-2000, sendo que em $85 \%$ das tempestades ele é menor que $500 \mathrm{~km}^{3}$, indicando que pequenas células predominam embora os volumes atinjam grandes valores. Obviamente não existem tempestades com volume menor que $30 \mathrm{~km}^{3}$ devido ao limiar definido inicialmente para o volume de uma tempestade, um parâmetro que compõe as condições para a identificação das áreas das células a serem rastreadas.

\subsection{2 Área}

Para cada tempestade identificada pelo limiar selecionado de $30 \mathrm{dBZ}$ foram calculadas as áreas médias. A área média é definida como a média da área em cada nível de altura através da extensão vertical da tempestade. A distribuição de freqüência para a área das tempestades que excedem o limiar de $30 \mathrm{dBZ}$, mostra uma distribuição lognormal truncada semelhante a do volume, com predomínio de pequenas células e uma área mediana de 72,0 e 82,5 km², Figuras 3a e 3b, respectivamente para os verões de 1998-1999 e 1999-2000. 


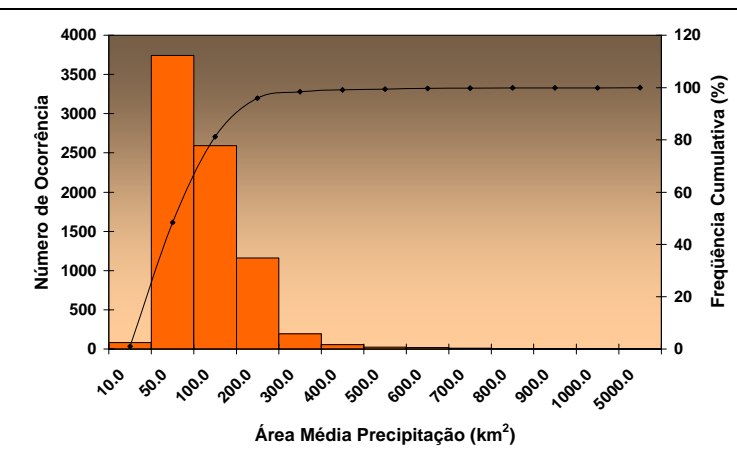

(a)

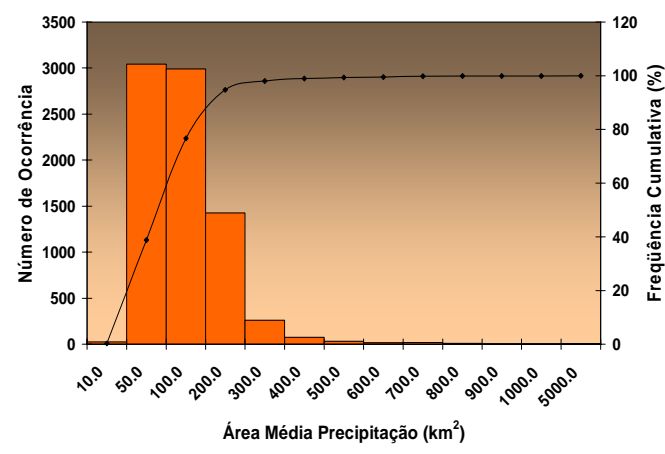

(b)

Figura 3 - Distribuição de freqüência para as áreas médias de precipitação durante os verões de (a) 19981999 e (b) 1999-2000, em intervalos de 1-10; 10,1-50; 50,1-100; etc.

Embora não houvesse um limiar mínimo para a área da tempestade no processamento dos dados, os limiares de volume e altura resultaram num limiar inferior para a área e num desvio da lognormal para pequenas áreas, evidente nos gráficos das distribuições resultantes. Houze e Cheng (1977) apresentaram uma análise das características das configurações dos ecos de radar o qual incluiu uma análise das dimensões horizontais dos ecos observados a partir de informações de varreduras com uma única elevação registradas sobre o oceano Atlântico tropical durante o Experimento GATE. Os resultados desse estudo foram incluídos aqui, bem como os resultados obtidos por Potts et al. (2000), que realizaram análise similar à do presente estudo para uma comparação entre os mesmos, conforme Tabela 1. 
Tabela 1 - Resultados experimentais de percentagens das áreas de ecos de radares de outros estudos comparados ao presente trabalho.

\begin{tabular}{|lccc|}
\hline Escala da Tempestade & A & B & C \\
\hline $\begin{array}{l}\text { Escala-D }\left(1-10^{2} \mathrm{~km}^{2}\right) \\
(\text { micro- } \alpha \text {-meso- } \beta)\end{array}$ & $67,0 \%$ & $64,0 \%$ & $80,9 / 76,9 \%$ \\
\hline $\begin{array}{l}\text { Escala-C }\left(10^{2}-10^{3} \mathrm{~km}^{2}\right) \\
(\text { meso- } \beta)\end{array}$ & $28,0 \%$ & $30,0 \%$ & $19,0 / 23,0 \%$ \\
\hline $\begin{array}{l}\text { Escala-B/C }\left(10^{3}-10^{5} \mathrm{~km}^{2}\right) \\
(\text { meso- } \alpha)\end{array}$ & $5,0 \%$ & $6,0 \%$ & $0,1 / 0,1 \%$ \\
\hline
\end{tabular}

A: Resultados extraídos de estudos realizados por Houze e Cheng (1977) para tempestades observadas durante o experimento GATE.

B: Resultados extraídos de estudos realizados por Potts et al. (2000) para tempestades observadas em Sidney, Austrália.

C: Resultados obtidos no presente estudo para tempestades observadas na área central do estado com o radar de Bauru.

A predominância de pequenos ecos, ou ecos da escala-D, nos três casos fica evidenciada, com uma percentagem de ocorrência relativamente maior para a região central do Estado, isto é, entre $15 \% \mathrm{e}$ $26 \%$ maior. Nos trópicos as respectivas escalas correspondem a ecos isolados, fusões de primeira ordem, e os de segunda ordem examinados por Simpson et al. (1993). Ecos de escala-D (10-10 $\mathrm{km}^{2}$ ) estão geralmente associados com tempestades unicelulares de curta duração e os ecos de escala-C $\left(10^{2}-10^{3} \mathrm{~km}^{2}\right)$ são predominantemente associados com tempestades multicelulares pequenas, e grandes tempestades unicelulares com circulação bem definida, que inclui as supercélulas. A escala - B/C $\left(10^{3}-10^{5} \mathrm{~km}^{2}\right)$ está associada a sistemas convectivos de mesoescala, tais como, linhas de instabilidade e grandes tempestades multicelulares contendo extensas áreas de chuva estratiforme.

Uma análise da frequência de ocorrência para as várias escalas de tempestade mostra uma boa concordância no que diz respeito ao predomínio de pequenas tempestades normalmente de curta duração, seguida por tempestades multicelulares e grandes tempestades que apresentam uma circulação bem definida. Tempestades da escala B/C aparecem na área central do Estado numa freqüência bem menor que as observadas durante o GATE e em Sidney, na Austrália. 


\subsubsection{Altura Do Topo Dos Ecos}

A distribuição de frequência para os topos máximos dos ecos considerando o limiar $30 \mathrm{dBZ}$, durante os verões de 1998-1999 e 1999-2000, é mostrada nas Figuras 4a e 4b, respectivamente. As frequências foram obtidas para cada incremento de $2 \mathrm{~km}$, sendo que a altura mediana observada para os topos foi de 11,0 e 8,4 km a.n.m.m, respectivamente. Em 85\% dos casos analisados durante o verão de 1998-1999 e em 90\% durante o verão de 1999-2000, as tempestades definidas pelo limiar maior que $30 \mathrm{dBZ}$, tem topo máximo observado durante o período menor ou igual a $12 \mathrm{~km}$.

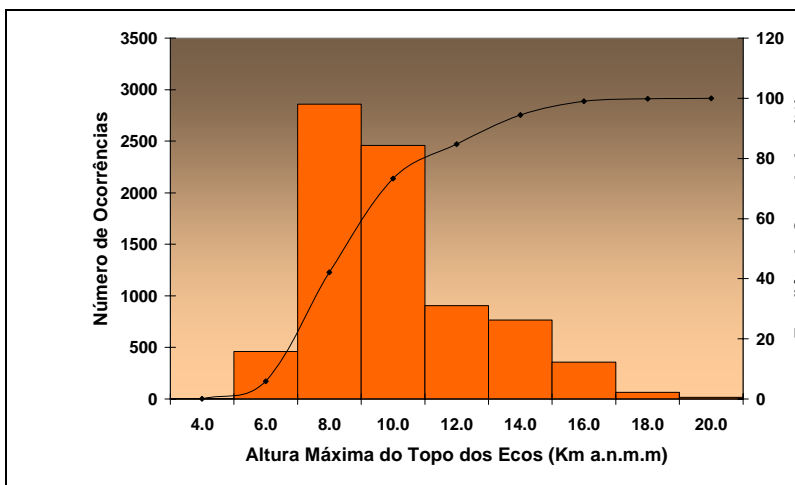

(a)

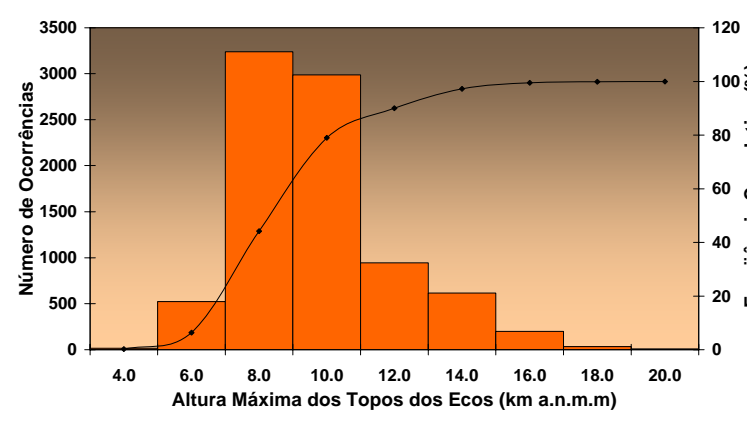

(b)

Figura 4 - Distribuição de frequência para os topos máximos dos ecos de $30 \mathrm{dBZ}$, em km acima do nível médio do mar (a.n.m.m), observados pelo radar Doppler de Bauru durante os verões de (a) 1998-1999 e (b) 1999-2000 em intervalos de 4,1-6,0; 6,1-8,0; 8,1-10,0; etc.

Se considerarmos que a distorção dos ecos de radar devido aos lóbulos secundários pode ser ignorada, mas que ainda existem retornos significativos do lado de fora do limite dos $3 \mathrm{~dB}$ do feixe do radar no caso em que a refletividade do alvo é alta e o gradiente de refletividade próximo ao topo da tempestade é grande, isto poderá causar uma super-estimativa do topo da tempestade.

A conversão dos dados em coordenada polar para coordenada cartesiana também poderá causar alguma distorção na estrutura vertical dos ecos tal que os topos podem ser superestimados (distantes do radar) ou subestimados (próximos ao radar), dependendo da localização das tempestades em relação ao radar. Os resultados mostrados através das Figuras $4 \mathrm{a}$ e $4 \mathrm{~b}$ indicam que o máximo topo observado foi $20 \mathrm{~km}$, com ocorrência de alguns casos de topos entre 16 e $18 \mathrm{~km}$. Entretanto, e para a maioria dos casos dos topos observados para as tempestades, isso deve estar no intervalo de 1 a $2 \mathrm{~km}$ da altura verdadeira do 
topo de $30 \mathrm{dBZ}$. A altura do topo dos ecos baseada no mínimo sinal detectável (MDS) para o radar se estenderá por vários quilômetros acima da altura do topo de 30 dBZ. DeMott e Rutledge (1998) em seu estudo mostraram que essa diferença pode variar desde alguns quilômetros até mais de $10 \mathrm{~km}$, sendo que a altura do topo das nuvens poderá se estender mais ainda.

\subsubsection{Refletividade Máxima}

As distribuições de frequência das máximas refletividades são mostradas nas Figuras 5a e 5b. Essas distribuições foram obtidas a cada incremento de $3 \mathrm{db}$, com uma refletividade máxima média de 47,4 e $46,9 \mathrm{dBZ}$, respectivamente.

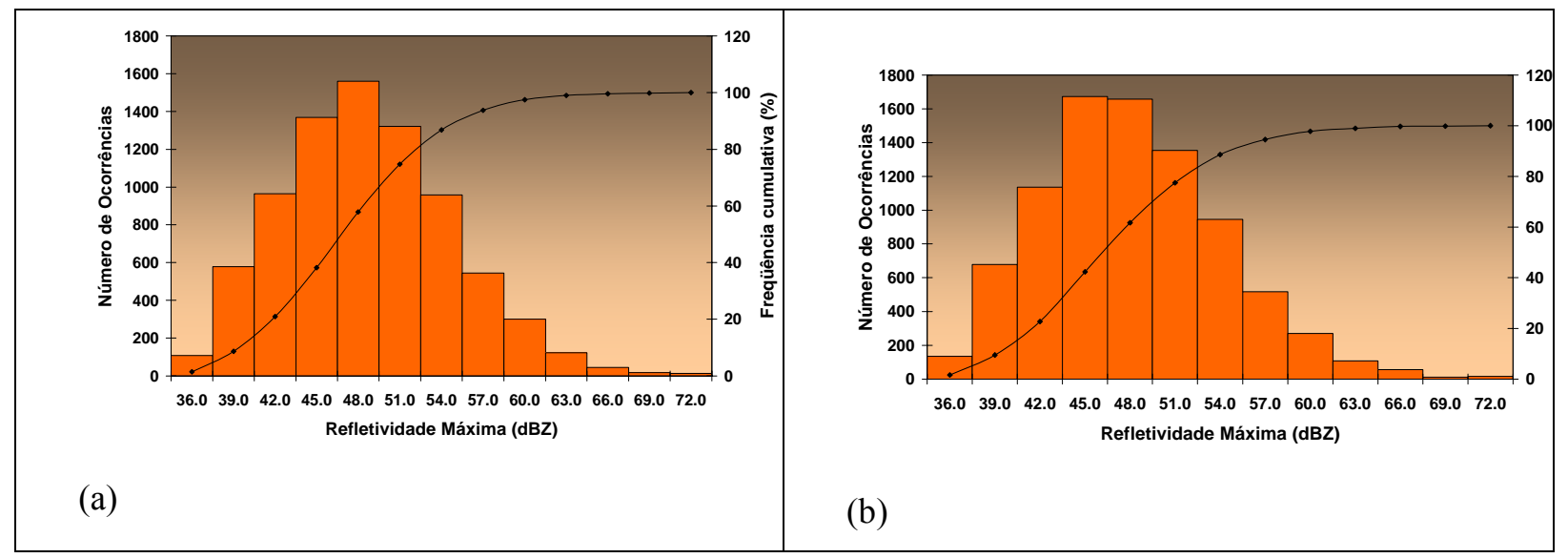

Figura 5 - Distribuição de frequência das refletividades máximas (dBZ), período do verão de (a) 1998/99 e (b) 1999/2000, observadas em cada tempestade de 30 dBZ, na área do radar Doppler de Bauru, em intervalos de 36,1-39,0;39,1-42,0; etc .

Analisando estes gráficos para as distribuições de freqüência tem-se que em $58 \%$ dos casos analisados durante o verão de 1998-1999 e em 62\% durante o verão de 1999-2000, para as tempestades definidas pelo limiar maior que $30 \mathrm{dBZ}$, observou-se que a refletividade máxima registrada foi menor ou igual a $48 \mathrm{dBZ}$.

\subsubsection{Deslocamento E Direção Das Tempestades}

O deslocamento das tempestades é basicamente dominado por três mecanismos: advecção pelo vento médio, propagação forçada pela presença de zonas externas de convergência em mesoescala e auto- 
propagação, onde a fluxo relativo de ar úmido em níveis inferiores ou gradientes verticais de pressão induzidos por tempestades, convergência e levantamento causam o desenvolvimento de novas células em direções preferenciais (ROTUNNO; KLEMP, 1982). Em muitos casos, mais de um desses mecanismos influenciará o movimento de uma tempestade durante seu tempo de vida. Pequenas tempestades são tipicamente advectadas pelo vento médio da camada enquanto que tempestades multicelulares, linhas de instabilidade, e supercélulas podem desviar consideravelmente do vento médio, dependendo grandemente dos perfis verticais de estabilidade e vento (ROTUNNO; KLEMP, 1982).

As distribuições de frequência para a velocidade e direção de deslocamento para todas as tempestades cujo limiar de refletividade excedeu a $30 \mathrm{dBZ}$, foram obtidas e os resultados representam os deslocamentos dessas tempestades dentro do raio de alcance dos $240 \mathrm{~km}$ do radar Doppler de Bauru. Estas distribuições de frequência são mostradas nas Figuras $6 \mathrm{a}, 6 \mathrm{~b}$ e 7a, 7b, respectivamente. A velocidade e direção representam um deslocamento que é um somatório da velocidade e direção do vento ambiente mais o vento relativo à tempestade.

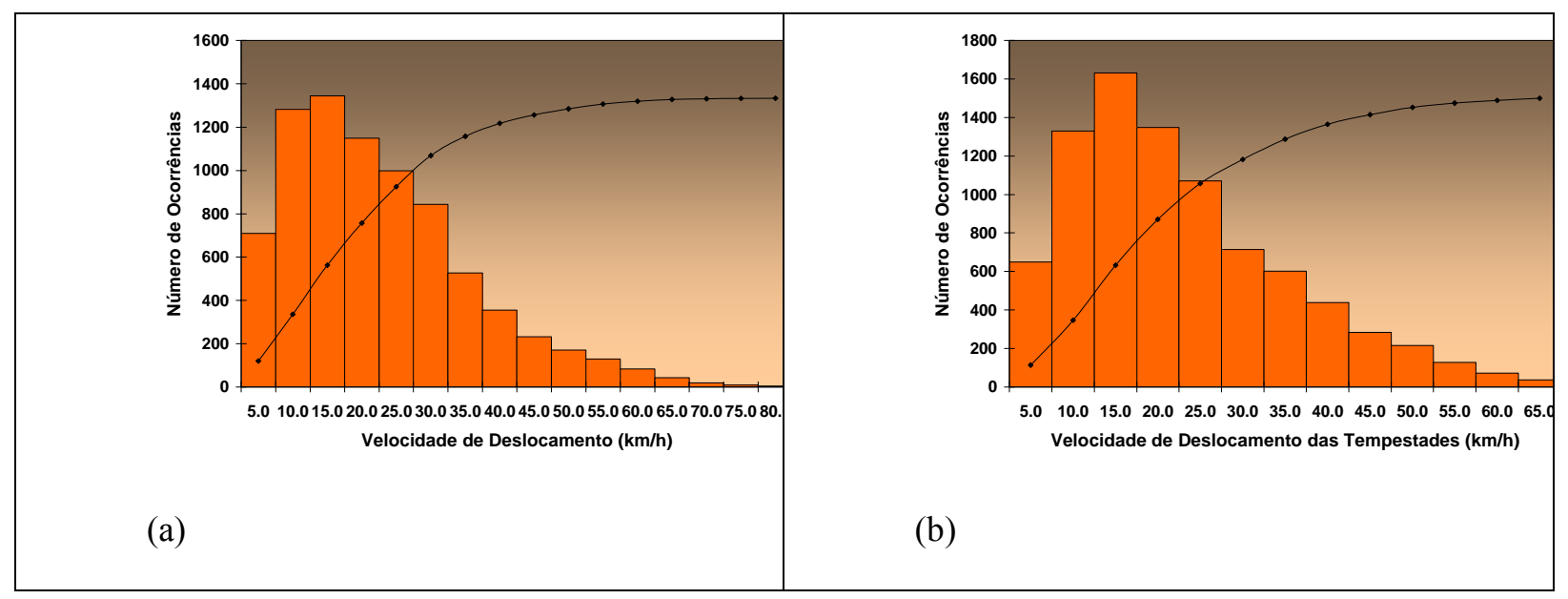

Figura 6 - Distribuição de frequência para as velocidades de deslocamento $(\mathrm{km} / \mathrm{h})$, durante o período dos verões (a) 1998/99 e (b)1999-2000, observadas para as tempestades excedendo 30 dBZ, na área de alcance do radar Doppler de Bauru, em intervalos de 5,1-10; 10,1-15,0; etc. 


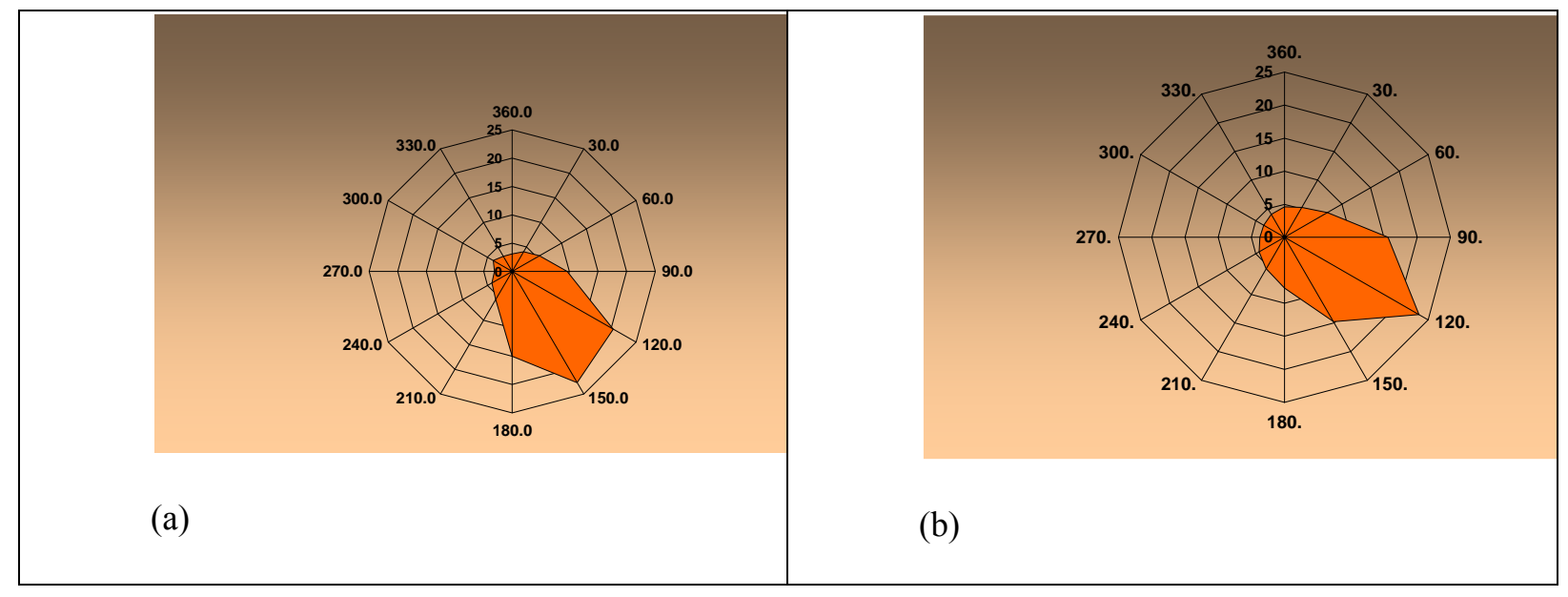

Figura 7 - Distribuição de frequência, por quadrantes de $30^{\circ}$, para onde se deslocam as tempestades, durante o período do verão (a) 1998/1999 e (b) 1999-2000, definidas pelo limiar de $30 \mathrm{dBZ}$, dentro da área de alcance do radar Doppler de Bauru.

A distribuição resultante das Figuras $7 \mathrm{a}$ e $7 \mathrm{~b}$ é semelhante em ambos os verões analisados, sendo que em $85 \%$ das tempestades observadas a velocidade de deslocamento dos sistemas precipitantes, definidos pelo limiar de $30 \mathrm{dBZ}$, é menor ou igual a $35 \mathrm{~km} / \mathrm{h}$, com uma direção predominante do setor nortenoroeste para o setor sudeste. Existem fatores adicionais que também poderão contribuir para os resultados observados, tais como a presença de tempestades numa dada área além de erros no rastreamento automático das células de tempestade usado no sistema de processamento dos dados. Estudos mais detalhados, considerando os movimentos das tempestades em relação ao vento médio ainda serão necessários para se examinar como os movimentos desses sistemas variam na região central do Estado, conforme demonstrado por Weisman; Klemp $(1982,1984)$.

\subsection{Climatologia Espacial Das Tempestades}

A distribuição espacial das tempestades durante os dois verões estudados é apresentada e discutida para o limiar de refletividade excedendo $25 \mathrm{dBZ}$, usando os campos resultantes para as distribuições de volume, área e refletividade máxima bem como para altura do topo dos ecos. 


\subsubsection{Volume Médio Sazonal De Precipitação}

Usando o módulo estatístico TrackGridStat do TITAN, que produz os campos médios em área obteve-se a distribuição espacial sazonal média para os volumes de precipitação observados pelo radar Doppler de Bauru durante os dois verões considerados.

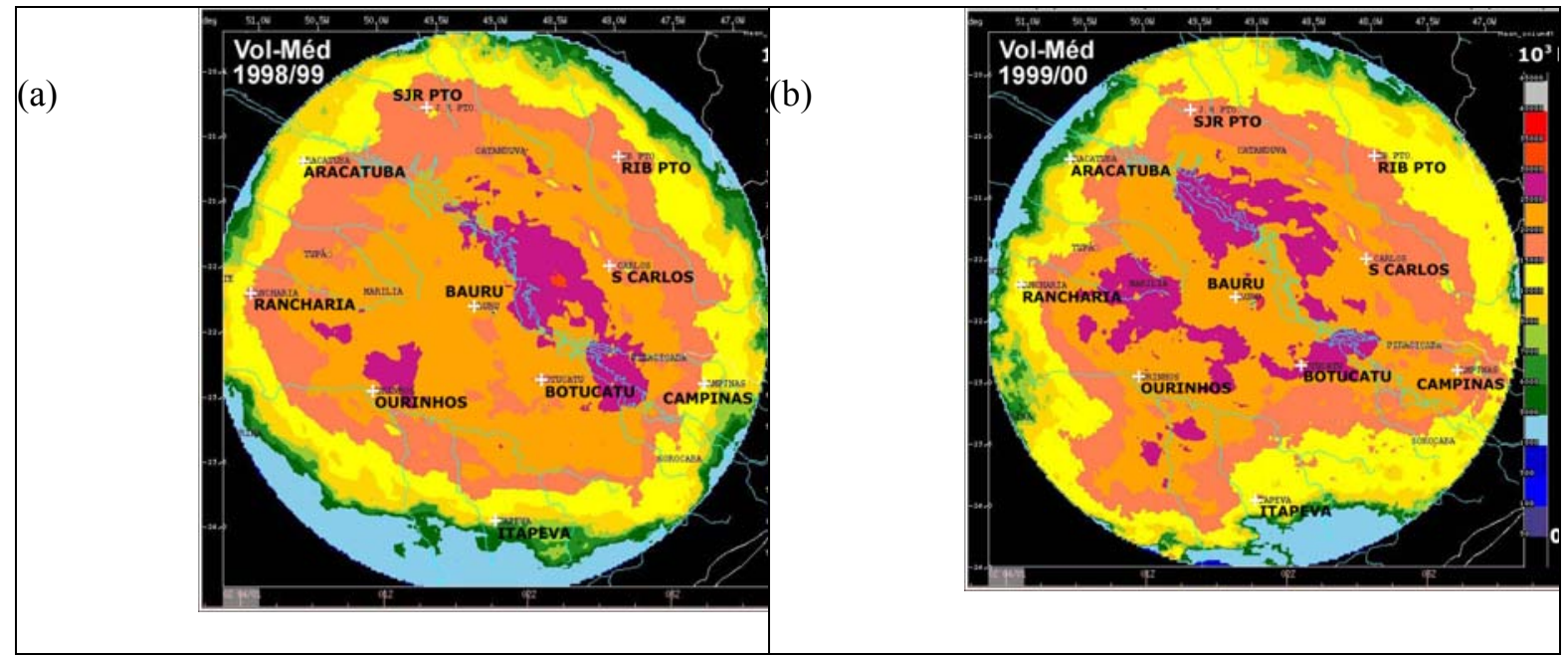

Figura 8 - Distribuição espacial sazonal dos volumes médios de precipitação $\left(10^{3} \mathrm{~km}^{3}\right)$, durante o período de (a) 01 de outubro de 1998 a 31 de março de 1999 e (b) 01 de outubro de 1999 a 31 de março de 2000.

As Figuras 8a e 8b representam essas distribuições resultantes para os períodos de 1998-1999 e 1999-2000, respectivamente. A análise para a distribuição espacial sazonal dos volumes observados evidencia as regiões onde se concentraram as maiores acumulações de precipitação, destacando a variabilidade espacial existente nesses volumes de chuva observados para o período estudado. As áreas mais favoráveis à concentração da atividade convectiva se localizam numa faixa paralela e orientada NWSE, ao longo do rio Tietê, favorecida pela presença do rio e ainda numa outra área próximo a região de Ourinhos, durante o verão de 1998-1999, Figura 8a. Os valores máximos sazonais observados dentro dessas regiões variaram entre 25 e $30 \times 10^{3} \mathrm{~km}^{3}$, em média. Em relação às demais regiões observa-se áreas mais homogeneas e com valores menores. A distribuição espacial dos volumes de precipitação para o período de 1999-2000, Figura 8b, mostra uma similaridade com a do verão anterior, no entanto exibe regiões onde o volume máximo de 25 e $30 \times 10^{3} \mathrm{~km}^{3}$ aparece sobre três áreas distintas, isto é, sobre a região de Botucatu, sobre a região de Marília e ao longo do rio Tietê mais localizado ao norte da região de Bauru. A determinação da distribuição espacial dos volumes de precipitação permitiria o acompanhamento e o 
conhecimento de como a precipitação se distribuiu dentro de uma área monitorada pelo radar. Além da informação da extensão de área tem-se também a informação de como esses núcleos de precipitação se distribuem sobre a região. A informação sobre a distribuição espacial dos volumes de precipitação, uma vez disponível, tem uma aplicação direta no monitoramento do déficit hídrico de uma dada região, dentro da área de alcance monitorada por radares meteorológicos. Os resultados obtidos reforçam a importância do monitoramento contínuo com o radar meteorológico sendo que a geração de campos relativos à distribuição espacial das diferentes propriedades relativas à precipitação se configura num produto de aplicação direta no auxílio do manejo de práticas agrícolas.

\subsubsection{Distribuição Espacial Das Áreas De Precipitação}

De modo similar, foram obtidas as distribuições espaciais para as áreas de precipitação durante o período selecionado, e estão apresentadas através das Figuras 9a e 9b, respectivamente.

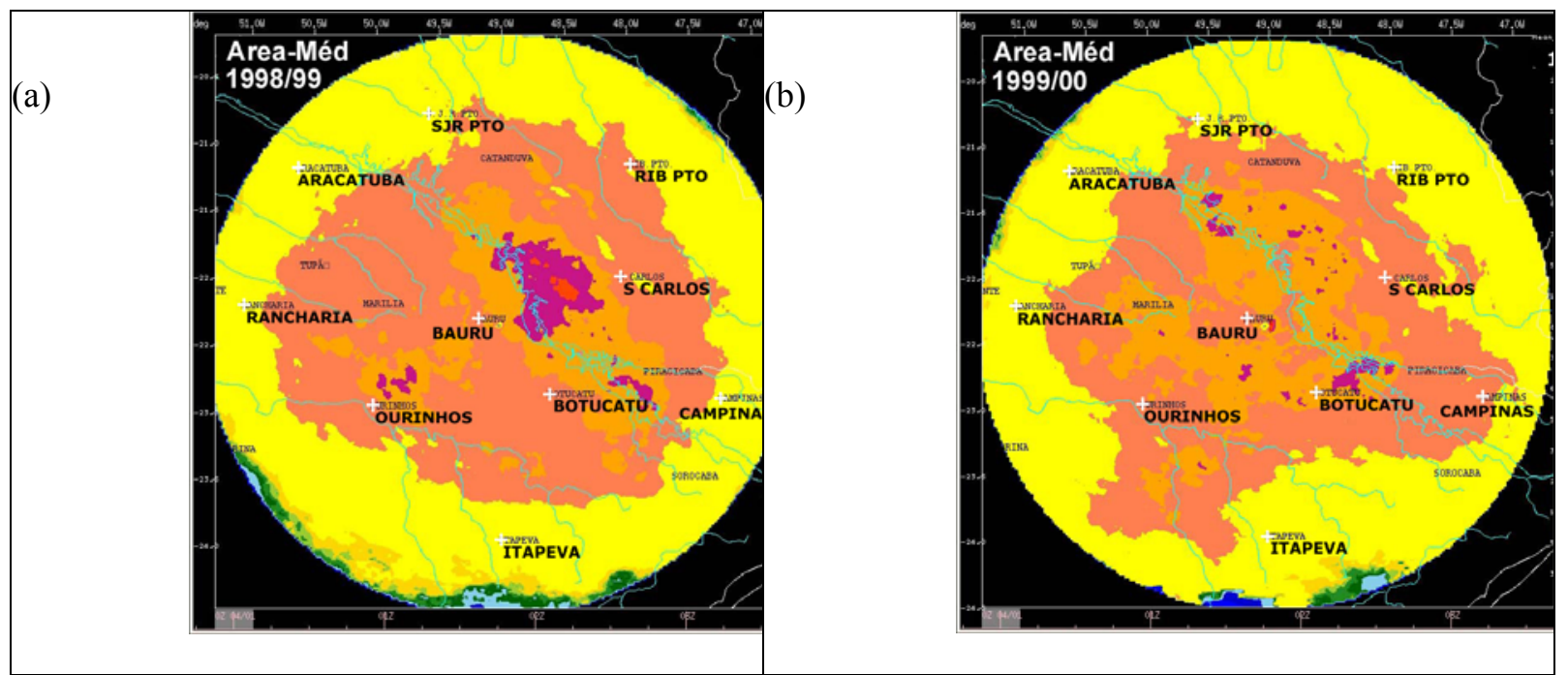

Figura 9 - Distribuição espacial das áreas médias de precipitação $\left(10^{3} \mathrm{~km}^{2}\right)$, durante o período de (a) 01 de outubro de 1998 a 31 de março de 1999 e (b) 01 de outubro de 1999 a 31 de março de 2000.

Em relação à distribuição espacial dessas áreas médias de precipitação observa-se um predomínio de sistemas precipitantes da escala-C de Houze; Cheng (1977), ou seja, tempestades multicelulares pequenas, cujas áreas variam de $10^{3}$ a $5 \times 10^{3} \mathrm{~km}^{2}$, em ambos os períodos. Os máximos valores sazonais de área média de precipitação variam de $7 \times 10^{3}$ a $10^{4} \mathrm{~km}^{2}$ e são observados ao longo do rio Tietê, durante o verão de 1998-1999 (Figura 9a), sendo que no período de 1999-2000 (Figura 9b), esses máximos apare- 
cem distribuídos em pequenas regiões situadas também ao longo do rio, evidenciando a ação de sistemas convectivos de mesoescala atuando durante o período, tais como linhas de instabilidade e grandes tempestades multicelulares com extensas áreas estratiformes.

\subsubsection{Distribuição Espacial Da Refletividade Máxima Média Dos Ecos De Precipitação}

A distribuição espacial sazonal para o campo médio das refletividades máximas associadas aos sistemas precipitantes observadas durante os dois períodos é apresentada aqui através das Figuras 10a e $10 \mathrm{~b}$.

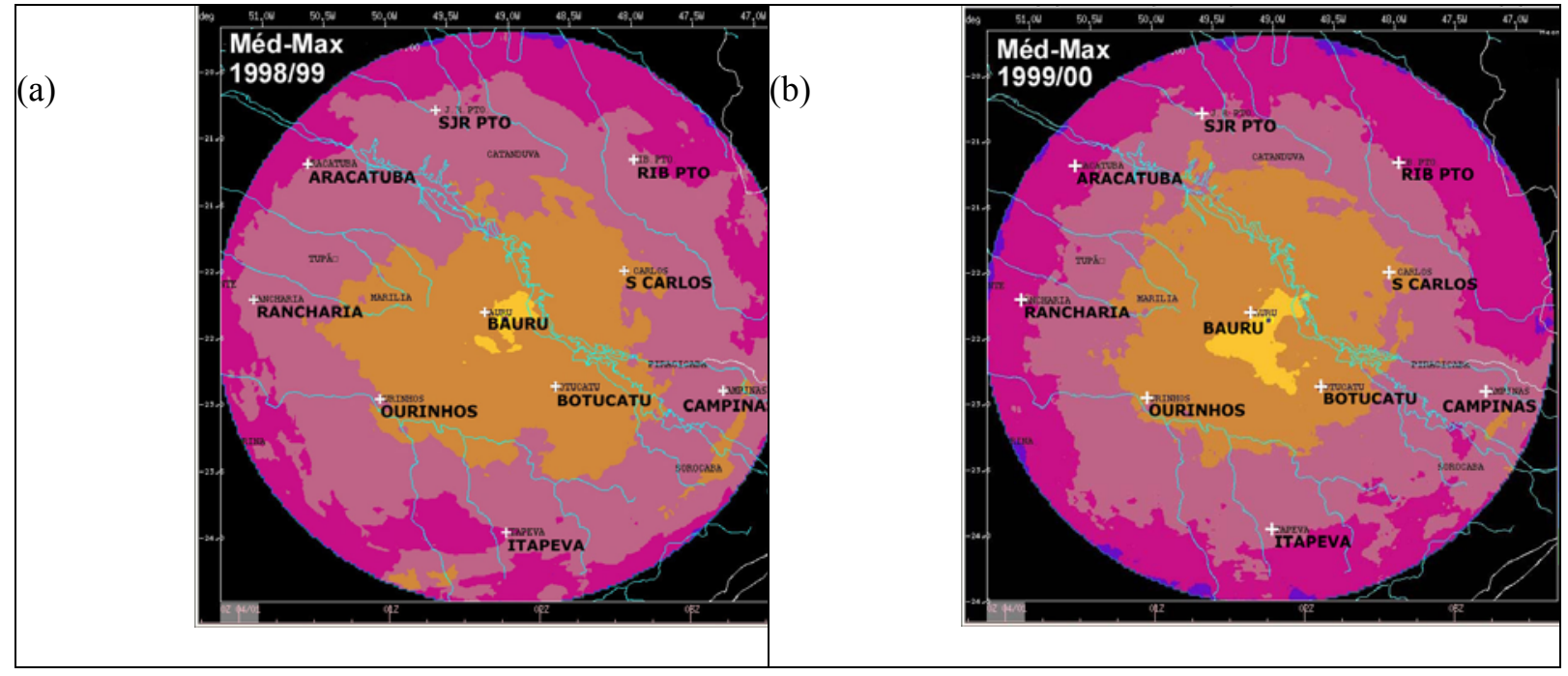

Figura 10 - Distribuição espacial para refletividade máxima média dos sistemas de precipitação (dBZ), durante o período de (a) 01 de outubro de 1998 a 31 de março de 1999 e (b) 01 outubro 1999 a 31 de março de 2000 .

Esses campos resultantes, em que somente são consideradas as áreas de tempestades que atingiram valores maiores que $40 \mathrm{dBZ}$, associados portanto aos eventos severos mais extremos, ocorridos na área de abrangência do radar de Bauru confirmam a existência de área preferencial de acumulação de grandes intensidades de precipitação sobre a região de Campinas, Figuras 11a e 11b, respectivamente. 


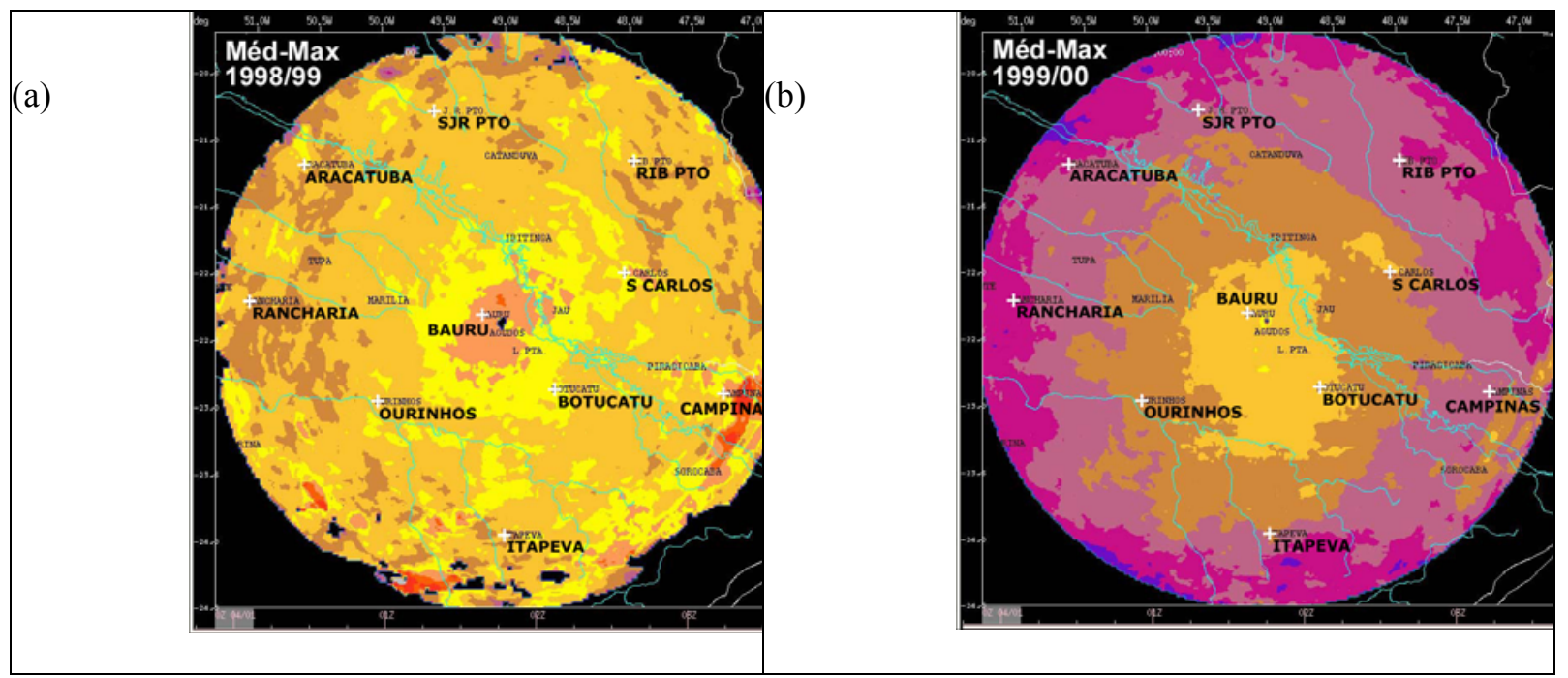

Figura 11 - Distribuição espacial para a média das máximas refletividades $>40 \mathrm{dBZ}$, durante o período de (a) 01 de outubro de 1998 a 31 de março de 1999 e (b) 01 de outubro de 1999 a 31 de março de 2000.

Um resultado importante extraído desses campos é que durante o verão de 1998-1999 (Figura 11a), se observou atividade convectiva mais intensa caracterizando um verão mais chuvoso do que o verão de 1999-2000, Figura 11b. Anomalias positivas de precipitação, obtidas com a rede convencional, foram observadas, para a área centro-oeste do Estado, durante os meses de Dezembro de 1998 a Fevereiro de 1999. Os núcleos de máximos de desvios positivos localizados no setor centro-oeste do Estado de São Paulo, com valores de $200 \mathrm{~mm}$ e no noroeste do Estado, $300 \mathrm{~mm}$, de acordo com os dados compilados pelo Centro de Previsão de Tempo e Estudos Climáticos (CPTEC, 2006).

O núcleo de máximas refletividades, excedendo a $60 \mathrm{dBZ}$, aparece bem definido sobre a região de Campinas na Figura 11a, observando-se também um núcleo de máxima, mas menos intenso, nessa mesma região durante o segundo período analisado, 1999-2000, Figura 11b. Os resultados do presente estudo, aplicando uma metodologia objetiva na determinação das áreas das células de tempestade confirmam os obtidos por Figueiredo (2005) sobre a distribuição espacial de refletividades observadas pelo radar de Bauru e reforçam os de Nacaratto et al. (2003), em seu estudo sobre a climatologia da distribuição espacial das descargas elétricas observadas no Estado de São Paulo. 


\section{CONCLUSÕES}

Os resultados do presente estudo indicam que as tempestades observadas pelo radar de Bauru durante o verão são compostas de células com volume médio entre 300,5 e $326,0 \mathrm{~km}^{3}$, sendo que em $85 \%$ das ocorrências esse valor foi menor que $500 \mathrm{~km}^{3}$. Em relação à extensão horizontal das áreas de chuva os resultados mostraram um predomínio de pequenas células de precipitação durante o período com valores medianos de 72,0 e 82,5 km², respectivamente para os verões de 1998-1999 e 1999-2000, usualmente associados a tempestades isoladas e de curta duração bem como tempestades multicelulares pequenas e grandes tempestades unicelulares, onde se inclui a categoria de supercélulas.

Os topos associados às tempestades observadas no período tiveram valores medianos de 11,0 e 8,4 $\mathrm{km}$, respectivamente. Em 85\% dos casos analisados em 1998-99 e em 90\% dos casos em 1999-2000 foi registrado topo menor ou igual a $12 \mathrm{~km}$. Para a refletividade máxima média foram observados valores de 47,4 e 46,9 dBZ, respectivamente, sendo que em 58\% dos casos analisados durante o verão de 1998-99 e $62 \%$ dos casos durante o verão de 1999-2000, observou-se uma refletividade máxima menor ou igual a $48 \mathrm{dBZ}$. A distribuição das velocidades de deslocamento e direção dessas tempestades em ambos os verões analisados é semelhante, com uma velocidade média de deslocamento de $25 \mathrm{~km} / \mathrm{h}$ e, predominantemente do setor noroeste para o setor sudeste.

A distribuição espacial sazonal desses parâmetros mostrou, pela primeira vez para a área central do Estado de São Paulo, como os mesmos se distribuíram pela área monitorada pelo radar Doppler de Bauru evidenciando regiões preferenciais de concentração de maior atividade convectiva, durante os períodos enfocados. A distribuição espacial sazonal do volume de precipitação mostrou um período convectivo mais ativo durante o verão de 1998-1999 em comparação ao período de 1999-2000, corroborado pelas áreas de precipitação observadas pela rede convencional. A proximidade de regiões de rios, aparece como um fator importante no favorecimento de áreas de concentração da atividade convectiva, que poderiam explicar a distribuição dos máximos localizados numa faixa paralela ao longo do rio Tietê, e numa área menor próxima a região de Ourinhos, na divisa com o estado do Paraná.

\section{REFERÊNCIAS}

CHAUDHRY, FAZAL HUSSAIN, ALCEU ANDRADE FILHO, ROBERTO VICENTE CALHEIROS.

Statistics on tropical convective storms observed by radar. Atmospheric Research, v. 42, p. 217-227, 1996. 
CENTRO DE PREVISÃO DO TEMPO E ESTUDOS CLIMÁTICOS. Resumo Sinótico para os meses de outubro de 1998 a março de 1999 e outubro de 1999 a março de 2000. Disponível em: http://climanalise.cptec.inpe.br/ rclimanl/boletim .Acesso em 10 nov. 2006.

DEMOTT, CHARLOTTE; STEVEN RUTLEDGE. The vertical structure of TOGA COARE convection. part 1: radar echo distribution. Journal of Atmospheric Sciences, Boston, v. 55, p. 2730-2747, 1998.

DIXON, MICHAEL; GEARY WIENER. TITAN: thunderstorm identification, tracking, analysis, and nowcasting: a radar-based methodology. Journal of Atmospheric Oceanic Technology, v.10, p. 785-797, 1993.

FIGUEIREDO, JOSÉ CARLOS. Pluviometria para a região central do Estado de São Paulo utilizando ecos de radar meteorológico. 2005. 134 f. Tese (Doutorado em Agronomia / área de concentração: energia na agricultura) - Faculdade de Ciências Agronômicas, Universidade Estadual Paulista, Botucatu, 2005.

GANDÚ, ADILSON WAGNER. Análise estatística de ecos de radar associados a precipitação na região leste do Estado de São Paulo. 1984. 161 f. Dissertação (Mestrado em Meteorologia) - Instituto de Astronomia, Geofísica e Ciências Atmosféricas, Universidade de São Paulo, São Paulo, 1984.

GOMES, ANA MARIA; GERHARD HELD. Characterization of storm properties during the TroCCiBras Experiment. In: RADAR METEOROLOGY CONFERENCE, 32, 2005, Albuquerque. Preprints... Albuquerque: American Meteorological Society, 4p., 2005.

HOUZE Jr, ROBERT; CHEE PONG CHENG. Radar characteristics of tropical convection observed during GATE: Mean properties and trends over the summer season. Monthly Weather Review, Boston, v. 105, p. 964-980, 1977. 
LÓPEZ, RAÚL. The lognormal distribution and cumulus cloud populations. Monthly Weather Review, Boston, v. 105, p. 865-872, 1977.

LÓPEZ, RAÚL. Internal structure and development processes of C-scale aggregates of cumulus clouds. Monthly Weather Review, Boston, v. 106, p. 1488-1494, 1978.

LÓPEZ, RAÚL et al. Population characteristics, development processes and structure of radar echoes in south Florida. Monthly Weather Review, Boston, v. 112, p. 56-75, 1984.

MARSHALL, JAMES STUART; WALTER PALMER. The distribution of raindrops with size. Journal of Meteorology, Boston, v. 5, p. 165-166, 1948.

NACARATTO, KLEBER ; OSMAR PINTO Jr.; IARA REGINA PINTO. Evidence of thermal and aerosol effects on the cloud-to-ground lightning density and polarity over large urban areas of southeastern Brazil. Geophysical Research Letters, Washington, DC, v. 30, n. 13, p. 71-74, 2003.

NACCARATO, KLEBER; OSMAR PINTO Jr; GERHARD HELD. Climatology of lightning in Brazil overview and comparison to the campaign period. In: HIBISCUS / TroCCiBras / TROCCINOX. WORKSHOP, 2004, Bauru. Proceedings... Bauru, Instituto de Pesquisas Meteorológicas, 2004, p- 10.

POTTS, RODNEY; THOMAS KEENAN; PETER MAY. Radar characteristics of storms in the Sidney area. Monthly Weather Review, Boston, v. 128, p. 3308-3319, 2000.

RAYMOND, WILLIAM. A theoretical evaluation of the relevance of lognormal distribution for the moisture flux and wind components. Monthly Weather Review, Boston, v. 125, p. 3018-3023, 1997. 
ROTUNNO, RICHARD; JOSEPH KLEMP. Influence of the shear induced pressure gradient on thunderstorm motion. Monthly Weather Review, Boston, v. 110, p. 136-151, 1982.

SIMPSON, JOANNE et al. Cumulus mergers in the maritime continent region. Meteorological Atmospheric Physics, Bonn, v. 51, p. 73-99, 1993.

WEISMAN, MORRIS; JOSEPH KLEMP. The dependence of numerically simulated convective storms on vertical wind shear and buoyancy. Monthly Weather Review, Boston, v.110, p. 504-520, 1982.

WEISMAN, MORRIS; JOSEPH KLEMP. Structure and classification of numerically simulated convective storms in directionally varying wind shears. Monthly Weather Review, Boston, v. 112, p. 2479-2498, 1984. 